\title{
EXTRACORONARY CARDIAC VEINS IN THE RAT ${ }^{1}$
}

\author{
MYRON H. HALPERN \\ Department of Anatomy, University of Michigan, Ann Arbor ${ }^{2}$ \\ SIX FIGURES
}

The present work had its inception in the discovery of vessels around the rat's heart which did not correspond to anything previously described in other mammals. These vessels are a system of veins which begin on the heart and terminate in the anterior venae cavae. Two major veins comprise this system, each of which crosses the midline to empty into the contralateral anterior vena cava. They drain the conal region of the right ventricle and the ventrocephalic region of the left ventricle. The term "extracoronary" cardiac veins has been applied to these vessels by the author because they originate on the heart and terminate in remote vessels not otherwise associated with the coronary circulation. Although this system has been found to exist in certain fishes and amphibians, to the author's knowledge it has never been recognized in mammals. These findings seemed to warrant a more detailed study of the adult cardiac venous drainage of the rat. To supplement this portion of the investigation, an embryologic study was undertaken. Both the adult and the embryonic patterns of the cardiac drainage were compared with the patterns found in the above vertebrates and were interpreted on the basis of these comparisons.

\section{MATERIAL AND METHODS}

For this study, the venous system of 85 adult rats were injected with latex preparatory to dissection. Of this number,

\footnotetext{
'Portion of a dissertation submitted in partial fulfillment of the requirements for the degree of Doctor of Philosophy in the University of Michigan.

${ }^{2}$ Present address: Department of Anatomy, Hahnemann Medical College, Philadelphia, Pa.
} 
17 injections were unsuccessful. In an effort to secure complete injection of the veins, which is often interfered with by the presence of blood clots, the following technique was used with excellent results. The rat was sacrificed with chloroform. The thorax was immediately opened by a mid-ventral incision through the sternum and the thoracic walls retracted. A cannula, a number 18 hypodermic needle one-fourth inch long, was inserted into the posterior vena cava as close to the diaphragm as possible, directing the tip of the needle cephalad into the heart. A ligature was placed around both the postcaval vein and the cannula. Between the needle and the syringe (a 25-ml veterinary syringe was used throughout) a piece of gum rubber tubing was interposed to act as a shock absorber and insure a steady injection flow. Prior to the latex injection, a $2 \%$ solution of warm citrated saline was introduced into the beating heart. Pressure was maintained until blanching was observed peripherally. The vascular system was then repeatedly flushed with tap water until the washings appeared clear. This procedure left the veins free of blood and at the same time relaxed the vessels. This was advantageous since it offset the contraction of the heart and vessels caused by the introduction of the ammoniated liquid latex.

For the venous system, a blue-green latex injection mass was used. This was prepared by diluting the commercial liquid latex with distilled water until the latex had the consistency of a thin cream. Several drops of ammonium hydroxide were added until there was a noticeable odor of ammonia. The pigment was prepared as a paste by adding a small amount of duPont Monastral Fast Blue ${ }^{3}$ to Glo-Craft Saturn Green ${ }^{4}$ fluorescent water-color paint until a blue-green color resulted. The pigment was stirred slowly into the diluted latex to avoid lumping and air-bubble formation.

\footnotetext{
${ }^{3}$ Obtained from E. I. duPont de Nemours and Company, Inc., Organic Chemicals Department, Wilmington, Delaware.

* Obtained from Switzer Bros., Cleveland, Ohio.
} 
During the injection, thumb pressure was carefully and steadily applied to the plunger of the syringe until the desired venous channels were filled. Pressure was then very slowly increased until blue pinpoint spots of effusion began to appear in the lungs. Extreme care was taken at this point in the application of the pressure to avoid the hazard of rupturing the veins. As quickly as possible after removal of the cannula, the ligature was tightened. Points of leakage or rupture could be plugged by coagulating the latex with a drop of hydrochloric acid.

Following the injection of the veins, the cannula and syringe were washed in ammoniated water and the arterial system was then similarly injected with a red mass. The needle was inserted into the aorta just below the level of the origin of the coeliac artery, directing its tip cephalad. Arterial injection was made directly without previous flushing. The red injection mass was prepared by adding to the diluted liquid latex a mixture of duPont Lithosol Fast Pink Paste and Glo-Craft Neon Red fluorescent water-color paint.

Following both injections, the animal was transected below the level of the coeliac artery. The thoracic portion was immersed in emblaming fluid $(2.1 \%$ formaldehyde, $33.3 \%$ alcohol, $8.3 \%$ glycerine, and $6.7 \%$ phenol, as used in the preservation of cadaver material). The specimens were left in the emblaming fluid a minimum of 24 hours before dissection was attempted in order to set the latex. (If speed is urgent, the setting process could be accelerated by acidifying the fixative.)

The dissections were all made under a wide-field binocular microscope. Each dissection was preceded by an exploratory examination under ultraviolet light of the $3500 \AA$ range which activated the fluorescent factor in the pigments of the injected vessels. For this, the objective of the microscope was fitted into a dark-box which was wired to receive a 6 -watt fluorescent type ultraviolet lamp. When the specimen was placed in this device, in the presence of the ultraviolet emanation, the course of the injected venous system was outlined by a green glow. The arterial system appeared with a red fluorescence. 
All the background material was dark by contrast. Since the ultraviolet penetrated the tissues slightly, the course of the vessels could be followed before dissection. This method made possible the detection of fine veins in situ without the risk of missing or destroying them in subsequent dissection. Additional doubly injected specimens were cleared and embedded in Ward's Bioplastic according to the following modification of the technique used in the Department of Anatomy of the University of Michigan. These specimens are fixed in acidulated $70 \%$ alcohol for 24 hours. They are then changed to $70 \%$ alcohol and left there for three to 4 days. At this point, it is well to place them in a $20 \%$ glycerine, $2 \%$ potassium hydroxide solution until the tissues begin to show signs of becoming jelly-like. Then a change is made to $70 \%$ alcohol to which several drops of hydrogen peroxide have been added. Leave the specimen in this solution until it becomes bleached, making several fresh changes. A transfer is made to $80 \%$ alcohol for one week, at the end of which time the specimens are placed in $95 \%$ alcohol for a week. Change to absolute alcohol for a minimum of one week. A final change is made into Cellosolve. ${ }^{5}$ After a specimen has sunk to the bottom of the container it is left in the Cellosolve an additional week. At the end of this time it is transferred to the uncatalyzed monomer of Ward's Bioplastic and placed in the refrigerator until the tissues have completely cleared. Finally the specimen is blocked by the methods outlined in Ward's manual.

\section{OBSERVATIONS}

Adult pattern of veins. Utilizing the technique described, 61 detailed dissections were carried out on the veins of the cardiac region. These were supplemented by 24 specimens which were either cleared and embedded or partly dissected. The left side of the conus, the origin of the pulmonary trunk, and the left atrium are drained by three channels which converge in the interval between the pulmonary trunk and the left atrium (fig. 1). The most ventral of these veins

${ }^{5}$ Obtained from Carbide and Carbon Chemical Corp., New York, N. Y. 
arises from numerous venules on the ventral side of the root of the pulmonary trunk, the left side of the pulmonary conus, and the adjacent basal portion of the left ventricle. The middle tributary is formed by the confluence of twigs draining

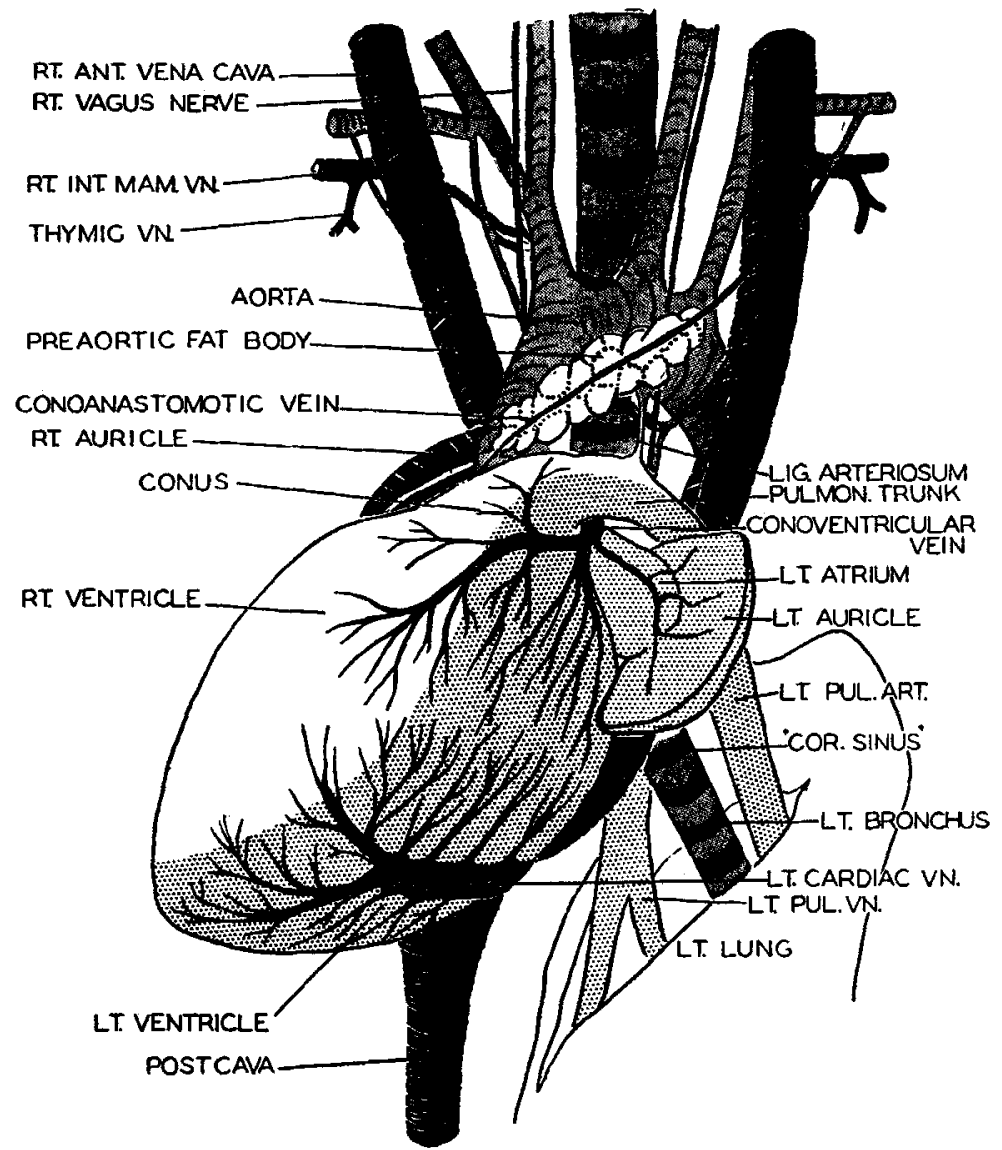

Fig. 1 Ventrolateral view of the adult rat heart showing the origin and distribution of the cardiac veins of the left side.

the lateral and dorsolateral areas of the basal region of the left ventricle. The most lateral branch arises on the auricular appendage by the convergence of several small veins. It receives in course several veins from the ventral side of the 
left atrium and then unites with the ventral and middle veins at the conoatrial junction to form the conoventricular vein. The conoventricular vein, lying on the cephalic portion of the left atrium, curves dorsal to the pulmonary trunk, passes dorsal to the root of the ascending aorta and opens into the

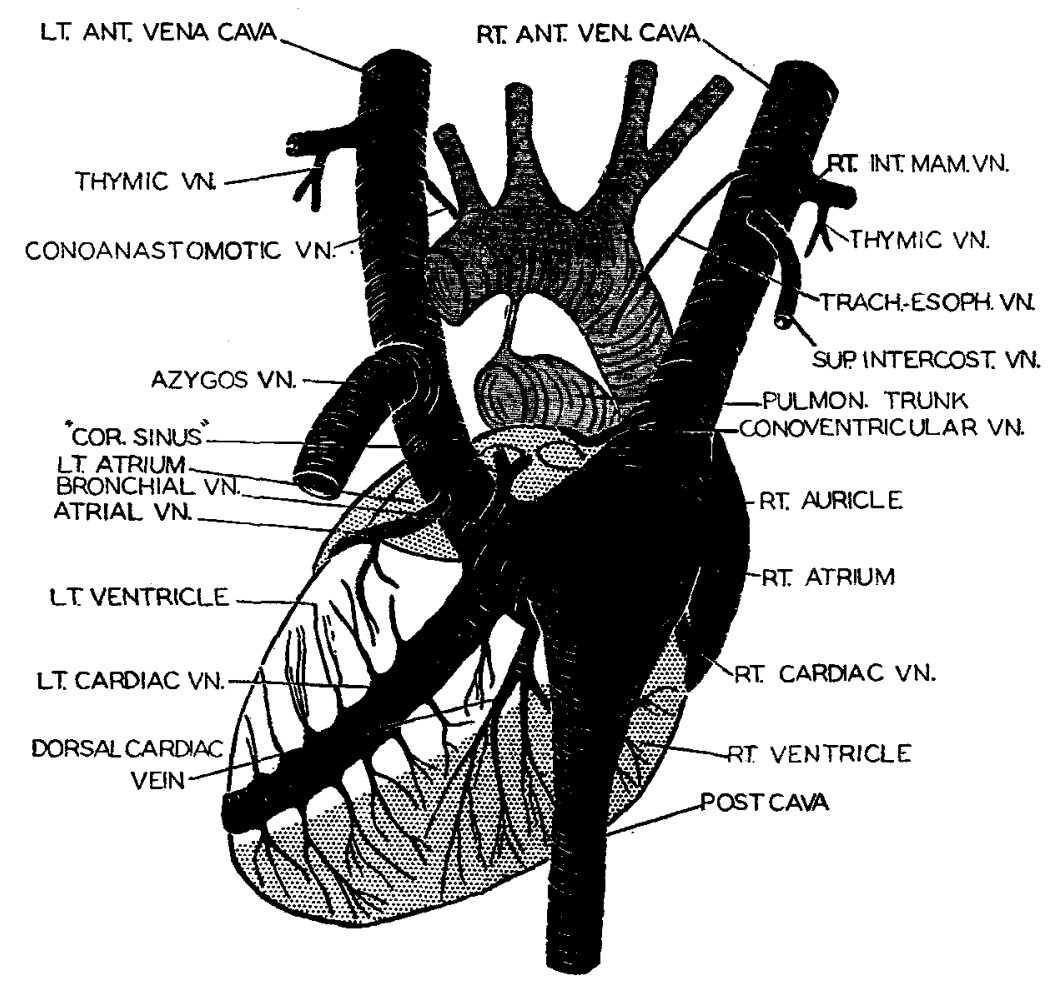

Fig. 2 Dorsal view of the adult rat heart showing the relationships of the veins draining into the "eoronary sinus" and into the right and left anterior venae cavae.

dorsomedial aspect of the base of the right anterior vena cava cephalic to the right atriocaval junction (fig. 2). This configuration is seen in all 68 specimens injected successfully.

The drainage of the region of the right side of the pulmonary conus and trunk begins as small tributaries that empty into the ventral cardiac vein which opens into the 
right atrium under cover of the right auricular appendage (fig. 3). The ventral cardiac vein is seen in 39 of the 68 fully injected specimens. The most cranial branch of the ventral cardiae vein drains the conus wall and anastomoses with a slender vein which lies embedded in the mass of preaortic fat. This anastomosis occurs in 19 of the animals. Thence it courses obliquely across the arch of the aorta to open into the ventral surface of the left anterior vena cava caudal to the point of entrance of the left internal mammary vein. This slender conoanastomotic vein drains the preaortic fat in addition to the right side of the conus myocardium. The conoanastomotic vein is found in 55 of the 69 animals injected successfully. Both the conoanastomotic vein and ventral cardiac vein are present in 8 animals without anastomoses. In 19 instances, when the conoanastomotic vein is present, the ventral cardiac vein is absent; and in 12 cases when the ventral cardiac vein is present, the conoanastomotic vein is lacking.

The apical portion of the ventral aspect of the heart is drained through veins which continue around onto the dorsal surface. The right ventricle is drained by the right cardiac vein which begins as many small veins arising in the right myocardium and converging into a single vessel (fig. 3 ). This vein then curves around the right ventricular margin to drain into the caudal portion of the right atrium under cover of the right auricular appendage. From the ventral side of the left ventricle and apex of the heart, small veins converge to form a wide trunk called the left cardiac vein. These small veins, by entering the left cardiac vein at almost right angles, present a striking pattern as they lie parallel to one another on the left ventricular wall (fig. 1). The left cardiac vein curves around the left border of the heart to reach the dorsal surface where it receives additional tributaries from the left ventricular wall (fig. 2). It runs cephalad across the dorsum of the heart to drain into the "coronary sinus" "

\footnotetext{
"The term "coronary sinus", is used to distinguish this structure, which in the rat is the entire left common cardinal vein, from the coronary sinus of luman anatomy representing only the proximal portion of the left common cardinal vein.
} 
just before the sinus opens into the right atrium. The remainder of the dorsum of the heart is drained by the dorsal cardiac vein which begins as many small veins on the middorsal and right dorsal regions of the heart. The small veins converge to form a short, stout trunk, the dorsal cardiac vein. This vessel also drains into the "coronary sinus" slightly

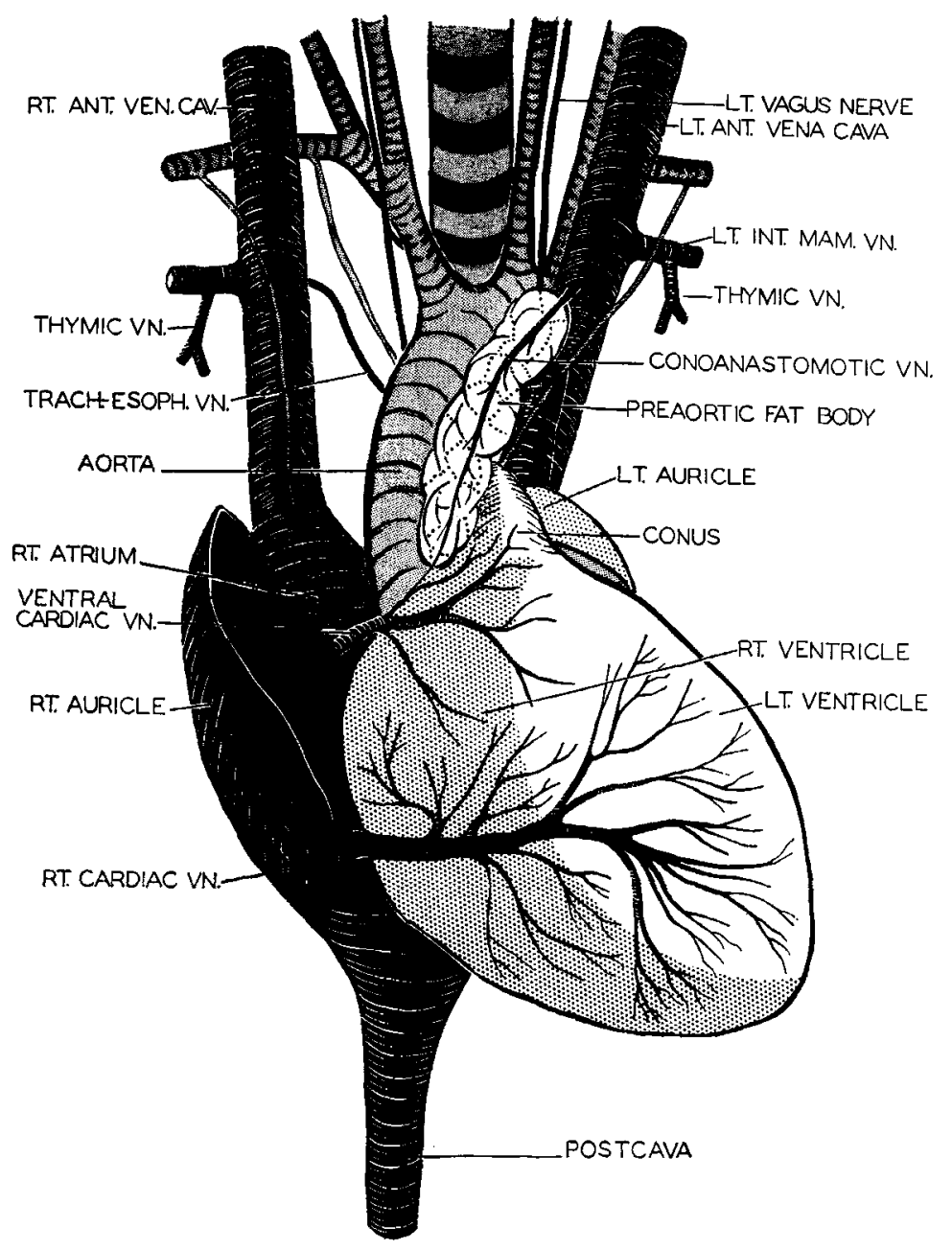

Fig. 3 Ventrolateral view of the adult rat heart showing the origin and distribution of the cardiae veins of the right side. 
to the right of the entrance of the left cardiac vein (fig. 2). The pattern of the dorsal, right, and left cardiac veins is constant in the 68 specimens. Two additional veins enter the "coronary sinus." As the sinus crosses the left atrium to gain the atrioventricular sulcus, the left atrial veins flow into it after draining the dorsum of the left atrium and a small area of the left cephalic corner of the dorsal surface of the left ventricle. From the mediastinum a bronchial vein drains into the dorsal side of the "coronary sinus" entering" just to the left of the site of termination of the left cardiac vein (fig. 2).

Developmental pattern of veins. The usual venous pattern, as well as the extracoronary drainage of the heart, must be interpreted in the light of the embryonic history of the region. For this embryological background a series of timed rat embryos was studied. For each age group, one transverse as well as one sagittal series was utilized. Examination of transverse sections of the 13-day rat embryo reveals a venous arch connecting the right and left anterior cardinal veins. This arch passes ventral to the pericardial cavity and ventral aorta running parallel to the 4 th aortic arch and receives, on its crainal aspect, tributaries from a venous plexus around the pharyngeal pouches. On its caudal aspect, it receives tributaries from the plexus of the ventral body wall. In the ventral mesocardium between the truncus and the ventral body wall, there are clusters of endothelial vesicles which seem to be primordial blood vessels developing in situ. These are also seen in the loose connective tissue filling the atrioventricular groove. At $\mathbf{1 4}$ days there is little change. Still paralleling the 4th aortic areh ventrally is the venous arch between the right and left anterior cardinal veins. This arch still receives tributaries from the ventral body wall but it has now become associated with the thymic primordia from the 3rd pharyngeal pouch which have migrated caudalward to a point ventral to the 4 th aortic arches. In the region of the 6th aortic arch, between the ventral aorta and the trachea, is a venous plexus draining into both anterior cardinal veins. 
At this stage the truncus has been partitioned to form the aorta and the pulmonary trunk, but a ventral mesocardium still attaches the pulmonary conus to the ventral body wall. In the loose mesenchyme surrounding the heart there occur endothelial vesicles or tubes containing nucleated blood cells. In the region of the atrioventricular sulcus, in addition to these blood-cell filled endothelial tubes, there are associated cell clusters (fig. 4) which may be less developed primordial

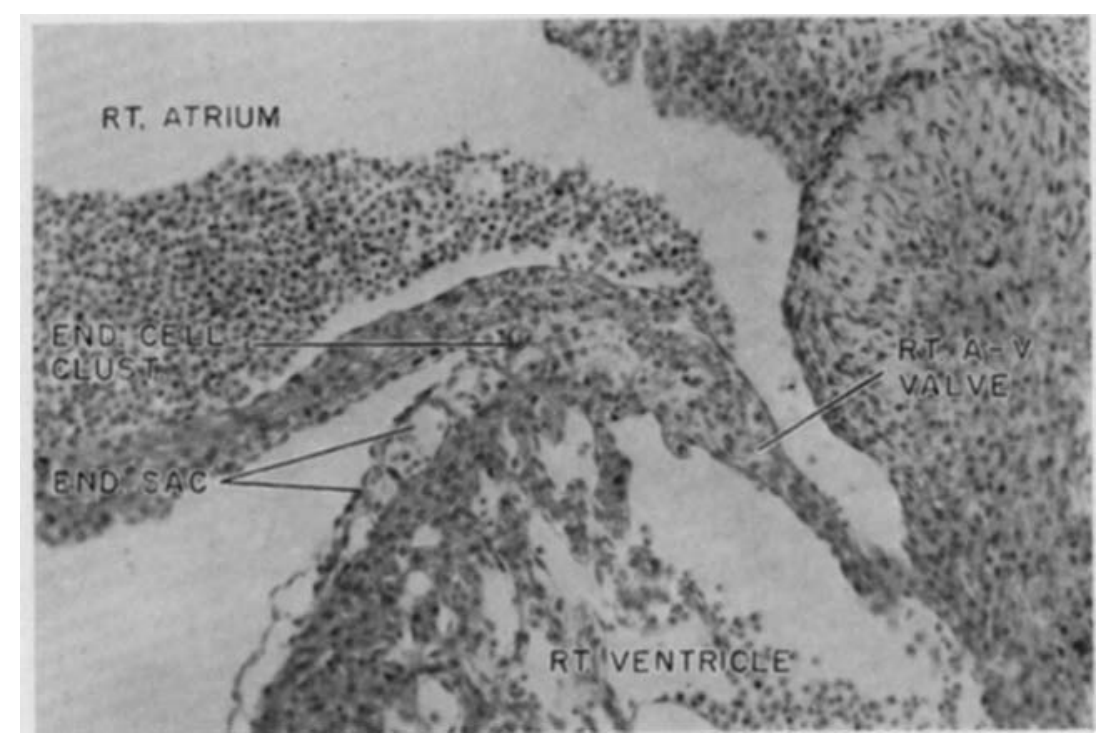

Fig. 4 Region of the right atrioventricular groove of 14-day rat embryo; note the endothelial vesieles and an endothelial cell cluster.

vascular channels taking shape in situ in the regions where the definitive cardiac veins later appear. Embedded in the mesenchyme of the right atrioventricular groove is a large blood-filled vesicle which is the primordium of the right cardiac vein. A similar vesicle lying in the mesenchyme in the groove between the left common cardinal vein and left ventricle opens into the left common cardinal vein caudally and is the primordium of the left cardiac vein. The left common cardinal vein passes obliquely to the right, dorsal to the 
left atrium, coursing between it and the pulmonary veins to open into the caudal part of the right atrium where sinus venosus and posterior vena cava enter. The right cardinal vein, on the other hand, opens directly into the sinus venosus.

Since extremely rapid growth and differentiation occur between 14 and 15 days, the 15-day embryo exhibits relationships and configurations which presage the direction in which the changes will proceed toward the adult condition. From the thymus, separate small veins enter the right and left anterior venae cavae (anterior cardinal veins). Around the arch of the aorta some of the endothelial tubes seen in the earlier stages now appear as a prominent plexus of veins best developed just ventral to the aorta (fig. 5). Becoming continuous with the preaortic plexus of veins is another venous plexus originating in the myocardium of the left ventricle to form a rete around the ascending aorta and the pulmonary trunk. Another plexus arising from the conus region extends onto the conus and around the ascending aorta. These venous plexuses as seen in the 13-day, 14-day and 15-day rat embryos arise primarily as buds on the heart which coalesce and anastomose to form channels along the routes of the definitive vessels. Secondarily these venous plexuses anastomose with the anterior cardinal veins (anterior venae cavae). Embedded in the loose connective tissue surrounding the ventricles and in the mesenchymal mass filling the atrioventricular groove, there are endothelial saes filled with embryonic blood cells. These sacs lie in positions along the course of the developing cardiac veins. As it traverses the dorsum of the heart, the left common cardinal vein ("coronary sinus") receives the left cardiac vein from the dorsal side of the left"ventricle, and a small venous bud off its ventral wall indicates the beginning of the dorsal cardiac vein. From these observations the venous drainage of the heart seems to have a double origin. First there are blood islands which hollow out to form endothelial sacs containing blood cells. These expanding sacs coalesce with each other to form endothelial tubes. Endothelial sprouts from the left common cardinal vein fuse 
secondarily with the spreading, anastomosing endothelial tubes to form the vessels which drain the ventricular myocardium into the "coronary sinus" and right atrium.

By 16 days several important changes have taken place. There is now a distinct double venous plexus around the

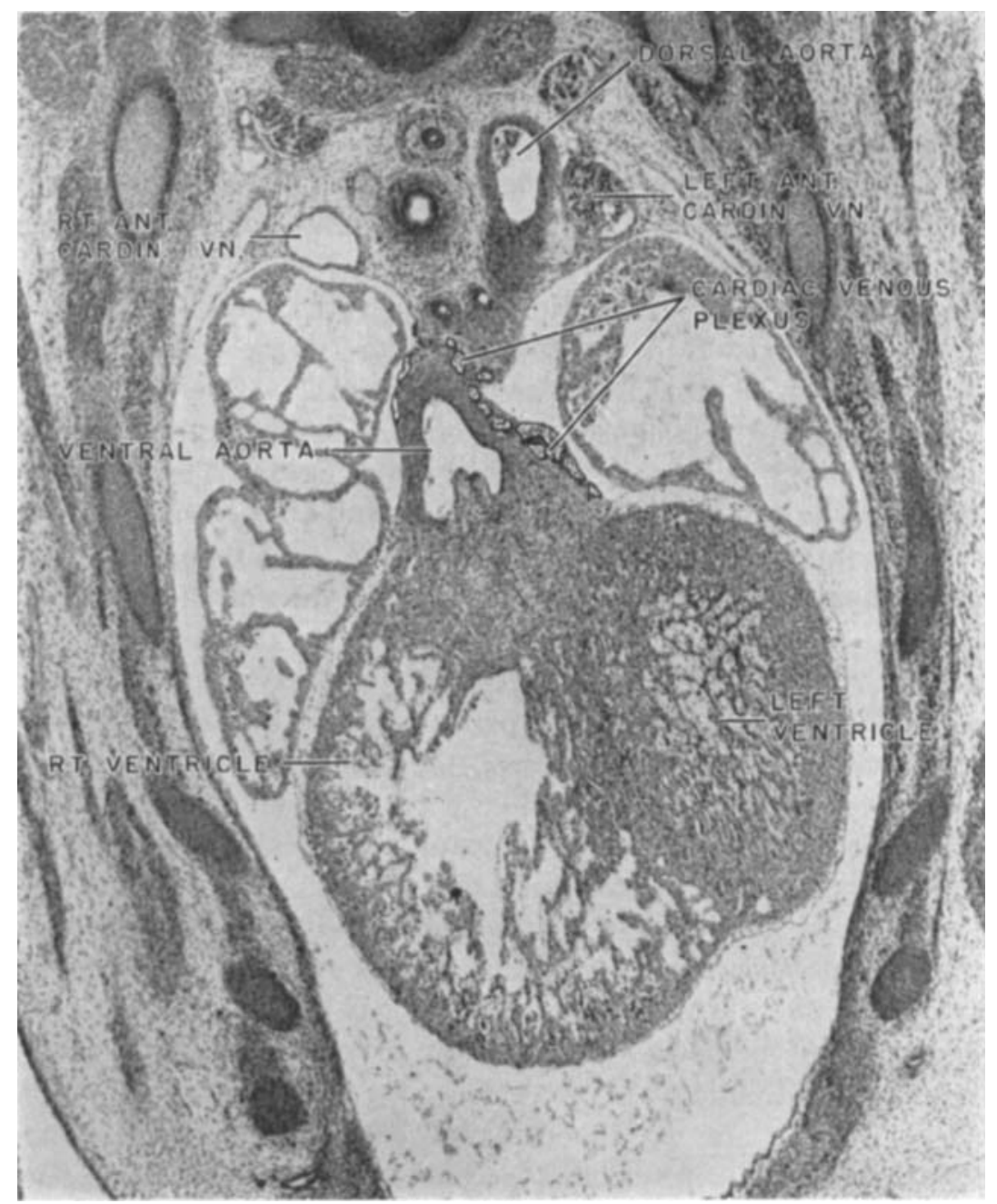

Fig. 5 Transverse section through the heart and great vessels of a rat embryo of 15 days showing the cardiac venous plexus. The venous plexus has been retouched. 
ascending aorta and the pulmonary trunk. Beginning on the left ventricle and on the underside of the left auricular appendage, a large anastomotic plexus of veins spreads over the left side of the root of the ascending aorta, coursing between the aorta and the pulmonary arteries to reach the dorsal and right side of the aorta. Passing ventral to the trachea, the plexus anastomoses with the right anterior vena cava at several levels. Veins originating on the right ventricle and conus, having passed as a plexus over the right side of the ascending aorta, also anastomose with the left plexus. The major part of the right plexus remains on the ventral side of the ascending aorta and the pulmonary trunk and passes diagonally across the aortic arch to open into the left anterior vena cava at the cephalocaudal level of the cranial end of the aortic arch. These right and left venous plexuses always pass ventral to the vagus nerve in draining into the right or the left anterior vena cava. Those tributaries that have passed dorsal to the vagus nerve in their drainage into the anterior venae cavae become the veins of the trachea and the esophagus. Three veins enter the "coronary sinus." On the left, where the "coronary sinus", first crosses into the atrioventricular sulcus, it receives the left cardiac vein. Where it opens into the right atrium, it receives the dorsal cardiac vein. At the extreme right, at its caudal tip, the "coronary sinus" receives the right cardiac vein. These vessels now show essentially their adult configuration.

Between 16 days and 16 days 14 hours, there is a loss of parts of the right and left venous plexuses of the earlier embryos. The rat embryo of 16 days 14 hours shows essentially the adult pattern. The major portions of the venous plexuses have dwindled to leave pervious only those channels which remain as the difinitive adult structures. The vessel which is the remains of the right venous plexus is the conoanastomotic vein. Beginning on the right ventricle and conus, it lies in the groove between the ascending aorta and the pulmonary trunk and extends onto the ventral face of the 
aorta between the pulmonary trunk and the ascending aorta (fig. 6). Thence it crosses the arch of the aorta diagonally to drain into the left anterior vena cava.

From the left ventricle, venous channels converge under cover of the left auricular appendage to form the cono-

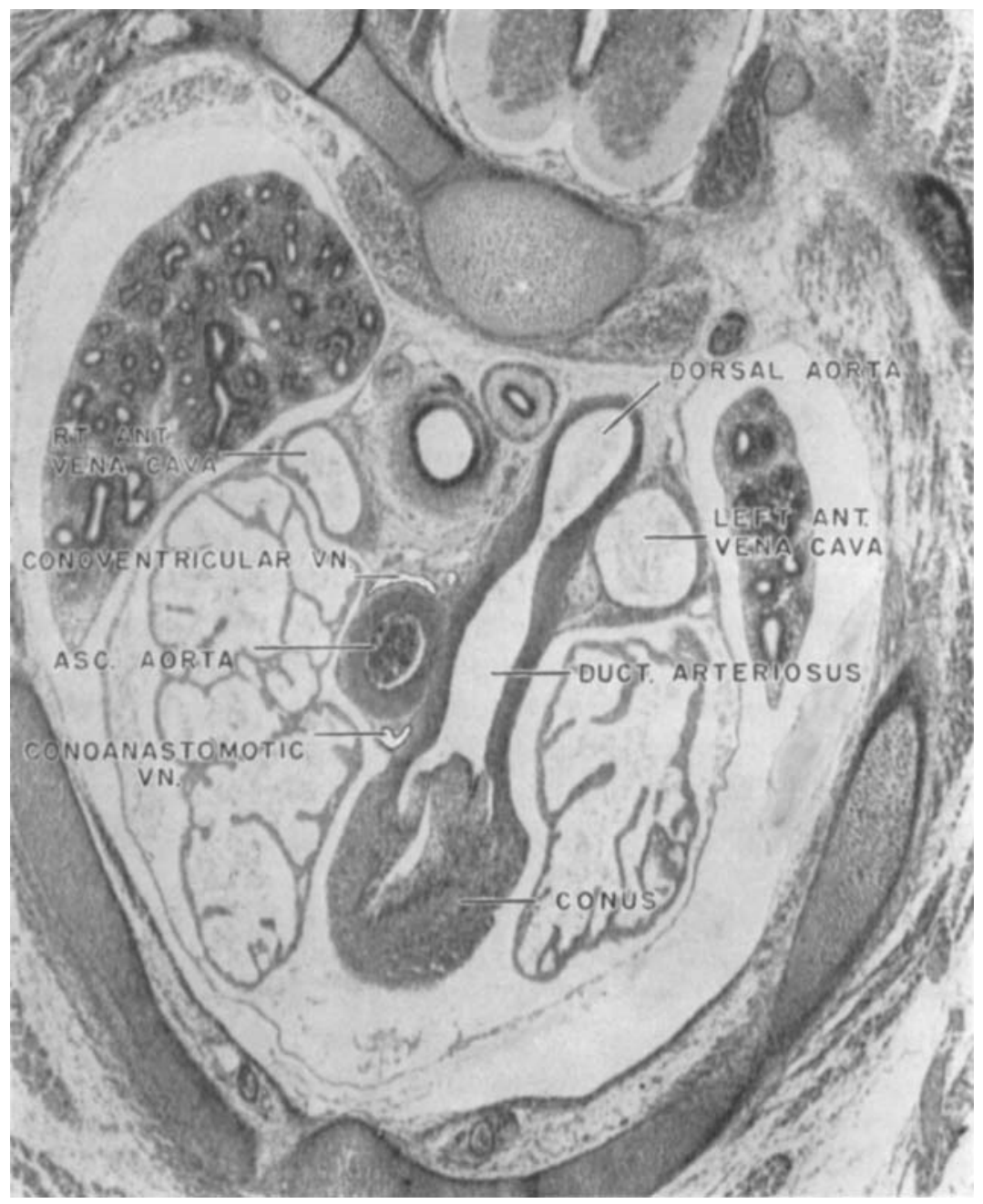

Fig. 6 Transverse section through the thorax of a rat embryo of 16 days 14 hours at the level of the ductus arteriosus. Relationships of the conoanastomotic and conoventricular veins are shown at this level. These veins have been retouched. 
ventricular vein lying against the left side of the root of the ascending aorta, between it and the pulmonary arteries. From this position it passes caudal to the ductus arteriosus to reach the interval between the trachea and the ascending aorta. The conoventricular vein then ascends for a short distance in this position and drains into the ventromedial angle of the right anterior vena cava opposite the level of the ductus arteriosus. Developmentally it is a remnant of the left venous plexus. The right, the left, and the dorsal cardiac veins already show the adult configuration.

\section{DISCUSSION AND CONCLUSIONS}

Although this study presents the first description of cardiac veins draining into vessels situated away from the heart as the normal configuration in a mammal, there have been suggestions that this type of organization might exist. Hill ('37), describing the morphology of the pocket gopher, suggested that the cardiac veins were not homologous to those in man since they emptied into the precavae. The only other mention of an extracoronary cardiac vein that was found in the literature was made by Goodman ('50) in his description of an anomalous vein in a cat. This vein was a mediastinal vessel which arose in the outer layers of the wall of the ascending aorta and then coursed through the mediastinum to enter the right anterior vena cava on its dorsal side at the point of junction of the right and left innominate veins.

In non-mammalian vertebrates, extracoronary cardiac veins seem to be relatively common supplement to the coronary drainage system. Daniel ('34) described the veins of the heart in elasmobranchs as being composed of three sets of vessels which enter the sinus venosus near the sinoatrial opening. The deep veins (Thebesian veins) enter the atrium directly. In the eel, Grant and Regnier ('26) described the cardiac veins as falling into two groups, cephalic and caudal. The cephalic veins are small, drain the upper end of the bulbus arteriosus, and form a right and left group each of which turns dorsally to open into the jugular vein of the 
corresponding side. The caudal veins are also arranged in right and left groups which drain the corresponding side of the ventricle and lower portion of the bulbus into the epigastric vein of its own side. In the eel, the cardiac veins are primarily extracoronary vessels. The caudal veins are the chief ones but they show a tendency to move toward the heart and lose their extracoronary character by opening into the sinus venosus.

In the amphibians, there may be present, according to Grant and Regnier ('26), a caudal and a cephalic system of cardiac veins. One or the other may be absent, but the caudal system is most constantly present. When both are present, they drain the bulbo-conus, but in general the cephalic veins drain the upper and the caudal veins the lower portions of the bulbus. All the cardiac veins anastomose freely, however. In the frog, Rana temporaria, Grant and Regnier found three cephalic veins, the most constant of which was the median. It lies on the ventral aspect of the upper end of the bulbus and the truncus, joins the pericardial veins to open into the veins of the unpaired "fatty body," and then drains into the external jugular vein of each side. The left and the right cephalic veins follow the course of the arterial trunks to open into the respective anterior vena cava or the subclavian vein.

In reptiles, especially turtles and lizards, Grant and Regnier ('26) found that the cardiac veins are also arranged in three groups. The right and left group drain the corresponding sides of the ventricle and the root of the aorta to unite into single stems in the atrioventricular groove of that side. The third or middle group ascends on the dorsal aspect of the ventricle. All of these veins unite in the base of the ventricle into a common stem which passes into the sinus venosus. There are apparently no cephalic veins draining the bulbus, the existing veins being representatives of only the caudal veins.

The mammalian representative chosen by Grant and Regnier to show the cardiac venous pattern was the rabbit. In the 
rabbit, the cardiac veins form 4 groups: (1) The veins draining the left side of the heart collect into the left cardiac vein which passes around the left atrioventricular groove to open into the base of the left anterior vena cava or the beginning of the coronary sinus. (2) The right cardiac vein, in the right atrioventricular groove, is formed by the veins of the right side of the heart and opens into the coronary sinus. (3) The dorsal or middle cardiac veins drain the dorsal surface of the heart and open into the coronary sinus in common with the right cardiac vein. (4) The veins draining the infundibulum of the right ventricle unite to open into the ventral aspect of the right atrium. In most other mammals the cephalic veins are greatly reduced or nearly absent. They may well have their representation in those pericardial veins carried along the aorta and pulmonary trunk. As far as is known at present, the rat shows the retention of the primitive venous relations more strikingly than any other mammal, since the region of the conus and the surface of the ascending aorta and pulmonary trunk are drained by two sets of veins. The one from the left side of the conus, the conoventricular vein, passes to the right anterior vena cava. The one from the right side of the conus, the conoanastomotic vein, crosses the aortic arch diagonally to open into the left anterior vena cava. The conoanastomotic vein corresponds in part to the position and course of the median cephalic vein in the frog. The conoventricular vein seems to retain the characteristics of the cephalic vein of the eel. From their position, areas of drainage, and method of development from a plexus around the bulbus, the conoanastomotic and conoventricular veins appear to be a retention of the primitive cephalic cardiac veins found in fishes and amphibians. The right, the left, and the dorsal cardiac veins of the rat are undoubtedly the representatives of the caudal cardiac veins described by Grant and Regnier in a number of non-mammalian vertebrates.

Phylogenetically, the cardiac veins of mammals seem to have originated almost entirely from the caudal group of 
veins of lower forms. The view that they arise ontogenetically as endothelial outgrowths of the sinus venosus which spread over the heart is held by several investigators. Lewis ('04) described the formation of the cardiac veins in Torpedo and the rabbit as sprouts from the sinus venosus which ultimately branch. Grant ('26) found in the rabbit that the cardiac veins are the first to appear on the heart. The earliest rudiments of these are seen in the $7-\mathrm{mm}$ rabbit embryo as endothelial outgrowths from the left horn of the sinus venosus. Similarly, Bennett ('36), in the 6-mm pig, described the earliest primordium of the cardiac veins as an endothelial outgrowth from the sinus venosus. Goldsmith and Butler ('37), however, described the middle cardiac vein as the first cardiac vein to appear arising in the 9-mm pig, as an endothelial bud from the ventricular border of the coronary sinus slightly to the left of the opening of the coronary sinus into the sinus venosus. By $12 \mathrm{~mm}$ all the cardiac veins were present, having arisen as buds from the coronary sinus. Goldsmith and Butler never found the veins to arise from the sinus venosus as did Lewis ('04), Grant ('26), and Bennett ('36).

Evidence from the embryologic phase of this study seems to indicate that endothelial budding is not the only process involved in the formation of the cardiac veins. The 13-day rat embryo (4-5 mm) does not yet show any endothelial budding from the left common cardinal vein. There are found, however, epicardially in the loose connective tissue filling the atrioventricular groove, endothelial vesicles in which may be found developing blood cells. At 14 days $(7-8 \mathrm{~mm})$, in addition to the endothelial sacs, there are clusters of cells lying in the atrioventricular sulcus. These cell clusters appear to be blood islands, which are hollowing out to form the endothelial saes sometimes containing blood cells. On the right side, an endothelial sac was found abutting against the right end of the left common cardinal vein. On the left side, there has been an evagination of the endothelial wall of the left common cardinal vein to fuse with one of the endothelial 
vesicles on the left side to start the formation of the left cardiac vein. By 15 days (about $10 \mathrm{~mm}$ ), there are present well defined right and left cardiac veins draining into the "coronary sinus" (left common cardinal vein). Between these two veins, there is an endothelial bud from the "coronary sinus" indicating the beginning of the dorsal cardiac vein. Spreading throughout the epicardium as an anastomotic plexus, the coalescing endothelial vesicles extend over the surface of the heart, becoming more definite in those regions where the main vascular channels are to form. By 16 days $(12-13 \mathrm{~mm})$, the right, the left, and the dorsal cardiac veins drain the caudal regions and dorsum of the ventricles into the "coronary sinus." These vessels have become more extensive, showing their definitive pathways by 16 days 14 hours $(15 \mathrm{~mm})$. It may be inferred from this that the formation of the cardiac venous drainage in the rat is not as simple a process as heretofore described for other mammals. There is retained in the rat the primitive arrangement of cephalic and caudal cardiac veins. The cephalic component retains its extracoronary connections, confining its drainage to the conus region in the adult rat and developing from plexiform primordia around the bulbus cordis in the embryo. The caudal cardiac veins drain the ventricles of the heart and pass dorsally to open into the "coronary sinus." They develop as epicardial cell clusters which are canalized and which coalesce with the endothelial evaginations from the "coronary sinus." There is, therefore, in both the adult and the embryonic patterns of cardiac drainage in the rat a striking example of the retention of very primitive phylogenetic characteristics which seem to be lacking in other mammals, at least in the adult stage.

\section{SUMMARY}

1. The cardiac drainage in the rat presents an unusual pattern in that the right side of the conus empties through the conoanastomotic vein into the left anterior vena cava after having obliquely crossed the arch of the aorta and hav- 
ing passed through the mass of preaortic fat. The left side of the conus and the left atrium drain into the right anterior vena cava by way of the conoventricular vein. Ventral and dorsal surfaces of both ventricles drain into the "coronary sinus" by way of the right, the left, and the dorsal cardiac veins. There may be present a ventral cardiac vein which anastomoses with the conoanastomotic vein.

2. The extracoronary cardiac veins begin as an extensive plexus surrounding the truncus and conus regions of the embryonic heart. This plexus, secondarily, becomes confluent with the anterior cardinal veins. Selective retention of parts of the plexus results in the characteristic adult extracoronary cardiac venous pattern.

3. The right, the left, and the dorsal cardiac veins develop epicardially from cell clusters which become hollowed out to form blood-filled endothelial sacs. Anastomoses of these sacs with each other and with endothelial buds from the "coronary sinus" form the cardiac veins.

4. The extracoronary cardiac veins represent the primitive cephalic cardiac veins of early phylogeny. The cardiac veins of the ventricle are representatives of the caudal cardiac veins of lower forms. The rat, therefore, shows a retention of the primitive features of cardiac drainage.

\section{ACKNOWLEDGMENTS}

To Doctor Burton L. Baker, I am deeply indebted for making available to me unlimited numbers of rats from his colony so that the constancy of the vascular pattern might be adequately demonstrated.

My sincerest appreciation is due to Professors Russell T. Woodburne and Bradley M. Patten for their many suggestions throughout the course of this investigation and for their critical reading of the manuscript.

\section{LITERATURE CITED}

BENNETT, H. S. 1936 The development of the blood supply to the heart in the embryo pig. Am. J. Anat., 60: 27-53. 
Danier, J. F. 1934 The Elasmobranch Fishes. Univ. of California Press. (Veins of the heart, pp. 215-216.)

GoLDSMITH, J. B., AND H. W. BUTLER 1937 Development of the cardiac-coronary circulatory system. Am. J. Anat., 60: 185-201.

Goodman, D. C. 1950 A persistent left superior vena cava and anomalous anastomosing mediastinal vein in a domestic cat. Anat. Rec., 108: $415-420$.

GRANT, R. T. 1926 Development of the cardiac-coronary vessels in the rabbit, Heart, 13 : 261-271.

Grant, R. T., AND M. RegNIER 1926 The comparative anatomy of the cardiac coronary vessels. Heart, 13: 285-317.

HrL, J. E. 1937 Morphology of the Pocket Gopher Mammalian Genus Thomomys. Univ. Calif. Pub. Zool,, 4Q: 81-172.

LEWIS, F. T. 1904 The question of sinusoids. Anat. Anz., 25: 261-279. 